\title{
Blood methanethiol in alcoholic liver disease with and without hepatic encephalopathy
}

\author{
C J MCCLAIN,* L ZIEVE, W M DOIZAKI, S GILBERSTADT, AND G R ONSTAD \\ From the Department of Medicine, Minneapolis Veterans Hospital and Hennepin County Medical Center, \\ University of Minnesota, Minneapolis, Minnesota, USA
}

SUMMARY Blood methanethiol and ammonia concentrations were measured in 16 healthy volunteers, 52 consecutive alcoholic cirrhotics without overt hepatic encephalopathy (HE), and 42 consecutive patients with alcoholic liver disease and overt HE. The mean concentration of blood methanethiol was significantly greater than normal in the cirrhotics without overt HE, and the means of both methanethiol and ammonia were significantly greater in the patients with than in those without overt HE. Only one patient with overt HE had both normal ammonia and methanethiol blood concentrations. Twenty of the patients with HE were followed serially. The directions of change in methanethiol and ammonia were consistent with the direction of change in mental status in $85 \%$ and $60 \%$ respectively. All of the patients who deteriorated and died had changes in blood methanethiol that correlated with the change in mental status. We conclude that blood methanethiol is a valuable adjunct to the ammonia determination in the evaluation of the patient with possible HE. It is especially helpful in following the course of a patient with hepatic encephalopathy, both as to prognosis and as an indicator of response to therapy.

Mercaptans are extremely toxic sulphur-containing compounds that appear to be largely derived from colonic bacterial metabolism of methionine. Like ammonia, mercaptans are normally efficiently removed by the liver but escape detoxification with hepatic failure or shunting of intestinal blood around the liver. Animal studies have shown that small amounts of mercaptans can cause reversible coma and can act synergistically with ammonia and fatty acids to enhance the toxicity of these substances. ${ }^{1}$ In 1955, Challenger and Walshe ${ }^{2}$ established the association of mercaptans with hepatic failure by isolating methanethiol (methyl mercaptan) from the urine of a woman in deep hepatic coma, and, in 1970, Chen and his colleagues ${ }^{3}$ reported a four-fold increase in breath methanethiol in patients with hepatic failure. Recently, a method for measuring mercaptans was developed that was sufficiently sensitive to detect methanethiol in the blood of patients for the first time. ${ }^{4}$ We have applied this method to patients with hepatic failure over the past two years and are now reporting the results of this initial experience.

\footnotetext{
*Address for reprint requests : Craig J McClain, MD, Gastroenterology Section, Veterans Administration Hospital, Minneapolis, Minnesota 55417, USA.

Received for publication 11 October 1979
}

\section{Methods}

Simultaneous measurements of blood ammonia and methanethiol were made in 16 healthy hospital employees, 52 consecutive hospitalised patients with alcoholic cirrhosis who did not have overt hepatic encephalopathy (HE), and 42 consecutive hospitalised patients with alcoholic liver disease who had overt encephalopathy. Of the latter patients with encephalopathy, all but four had cirrhosis, the remainder alcoholic hepatitis without cirrhosis.

Twenty of the 42 patients with overt HE were followed serially - that is, evaluated with clinical ratings of severity of the encephalopathy and simultaneous measurements of blood ammonia and methanethiol three or four times during the course of their hospitalisation. The intervals between examinations varied from case to case. Encephalopathy was graded by a modification of the criteria of Parsons-Smith et al. ${ }^{5}$ as follows: grade 0 -no detectable abnormality at bedside examination. Grade I-trivial lack of awareness, euphoria, or apathy; shortened attention span, irritability, restlessness. Grade II-general worsening of grade I, personality change, lethargy, mild neurological changes (especially asterixis). Grade III-confusion, disorientation, somnolence. Grade IV-coma, responsive or un- 
Table 1 Some characteristics of the patients with liver disease

\begin{tabular}{|c|c|c|c|}
\hline & No $H E$ & $H E$ & $\begin{array}{l}\text { HE followed } \\
\text { serially }\end{array}$ \\
\hline $\begin{array}{l}\text { Number } \\
\text { Age (yr) }\end{array}$ & 52 & 42 & 20 \\
\hline $\begin{array}{l}\text { Mean } \pm S D \\
\text { Range }\end{array}$ & $\begin{array}{l}55 \pm 9 \\
26-71\end{array}$ & $\begin{array}{l}55 \pm 8 \\
40-79\end{array}$ & $\begin{array}{l}53=7 \\
40-67\end{array}$ \\
\hline Sex & & & \\
\hline $\begin{array}{l}\% \text { male } \\
\text { Liver biopsy available }\end{array}$ & 96 & 95 & 95 \\
\hline $\begin{array}{l}\% \\
\text { Previous HE }\end{array}$ & 80 & 83 & 90 \\
\hline Bilirubin $(\mu \mathrm{mol} / \mathrm{l})$ & 27 & - & - \\
\hline $\begin{array}{l}\text { Mean } \pm \text { SD } \\
\% \leqq 4.0 \\
\%>4.0\end{array}$ & $\begin{array}{l}34 \pm 34 \\
85 \\
15\end{array}$ & $\begin{array}{l}258 \div 214 \\
26 \\
74\end{array}$ & $\begin{array}{l}222 \pm 178 \\
30 \\
70\end{array}$ \\
\hline Albumin (g/l) & & & \\
\hline $\begin{array}{l}\text { Mean } \pm \text { SD } \\
\% \leqq 3.0 \\
\text { Prothrombin time (s) }\end{array}$ & $\begin{array}{l}34=6 \\
27\end{array}$ & $\begin{array}{l}28 \pm 7 \\
68\end{array}$ & $\begin{array}{l}28=7 \\
60\end{array}$ \\
\hline$\underset{\%>14}{\operatorname{Mean} \pm \text { SD }}$ & $\begin{array}{l}13 \cdot 6 \pm 1 \cdot 5 \\
36\end{array}$ & $\begin{array}{l}16 \cdot 0 \pm 2 \cdot 6 \\
76\end{array}$ & $\begin{array}{l}15.9=2.6 \\
85\end{array}$ \\
\hline $\begin{array}{l}\text { Ascites } \\
\% \\
\text { Died }\end{array}$ & 45 & 78 & 75 \\
\hline$\%$ & 0 & 60 & 65 \\
\hline
\end{tabular}

responsive to painful stimuli. The clinical evaluation of the patients was made before the blood was drawn for the ammonia and methanethiol measurements, and the person performing the laboratory tests knew nothing about the patients' clinical status. The patients were treated with protein restriction, neomycin, lactulose, or combinations thereof.

As the patients were unselected after being admitted to hospital, there was the expected association between severity of liver disease and the presence of encephalopathy (Table 1). Of the 52 cirrhotics without overt $\mathrm{HE}$, approximately one-half had ascities and one-quarter a previous episode of encephalopathy from which they had recovered. As a group their liver disease was less severe than that of the HE group as assessed by the serum bilirubin, albumin, prothrombin time, and the presence or absence of ascites. None of these patients died during the hospitalisation period in which our studies were made, whereas $60 \%$ of the 42 patients with overt HE died.

The whole blood ammonia was measured by a modified Conway diffusion method. ${ }^{6}$ The upper limit of normal in our laboratory was $90 \mathrm{nmol} / \mathrm{ml}$. Methanethiol was measured by the improved method of Doizaki and Zieve. ${ }^{4}$ The upper limit of normal was $550 \mathrm{pmol} / \mathrm{ml}$. All values in the 16 healthy employees we studied fell within these limits. The gas chromatographic method for methanethiol used a flame ionisation detector. Since recovery of methanethiol varies with the amount present, corrections for recovery were made each time based upon recovery curves such as those previously described in our method paper. ${ }^{4}$ The recovery curves were fairly reproducible. Repeat determinations on individual blood samples varied by as much as $15 \%$, the average being $6 \cdot 1 \pm 3 \cdot 6 \%$ (mean $\pm \mathrm{SD}$ ). One hundred blood samples kept frozen were later run using the flame photometric sulphur-specific detector. The correlation between the two procedures was 0.97. The actual values with the sulphur detector were slightly higher; the average difference, however, was only $8 \cdot 2 \pm 6 \cdot 7 \%$.

Ten of the 52 patients without overt hepatic encephalopathy, unselected except for convenience of study, were retested one week later in order to evaluate the variability of blood ammonia and methanethiol in patients showing no significant change in clinical status. Table 2 gives the test-retest values for blood ammonia and methanethiol. The

Table 2 Test-retest values in 10 clinically stable cirrhotics without $H E$

\begin{tabular}{lll}
\hline Test period & $\begin{array}{l}\text { Blood ammonia } \\
(\mathrm{nmol} / \mathrm{ml})\end{array}$ & $\begin{array}{l}\text { Blood methanethiol } \\
(\mathrm{pmol} / \mathrm{ml})\end{array}$ \\
I & $79 \pm 25$ & $516 \pm 68$ \\
II & $77 \pm 34$ & $501 \pm 75$ \\
\hline
\end{tabular}

Test periods were one week apart.

Means $\pm S D$ are given.

mean values show no significant change. However, individual values of both measurements, particularly the blood ammonia, varied considerably. Thus the average of the absolute differences (disregarding signs) between the test-retest values of blood ammonia was $30 \pm 19 \mathrm{nmol} / \mathrm{ml}$ (mean $\pm \mathrm{SD}$ ), and the upper $95 \%$ confidence limit (mean $+2 \mathrm{SD})$ for the absolute differences was $69 \mathrm{nmol} / \mathrm{ml}$, or $78 \%$ of the span of normal. Likewise the average of the absolute differences between the test-retest values of blood methanethiol was $51 \pm 34 \mathrm{pmol} / \mathrm{ml}$, and the upper $95 \%$ confidence limit was $119 \mathrm{pmol} / \mathrm{ml}$, or $22 \%$ of the span of normal.

\section{Results}

Mean concentrations of both blood ammonia and methanethiol were significantly increased in patients with $\mathrm{HE}$ when compared with healthy volunteers $(t>5.5, \mathrm{P}<0.001)$ and cirrhotics without overt HE $(t>4.5, \mathrm{P}<0.001)$ (Fig. 1). Individual values for blood methanethiol and ammonia in patients with and without $\mathrm{HE}$ are shown in Fig. 2. The correlation between the two measurements in these patients is insignificant. The outward distribution in the twodimensional plot of the cases with overt $\mathrm{HE}$, and the overlap between groups is apparent. The highest blood methanethiol concentration was 2110 


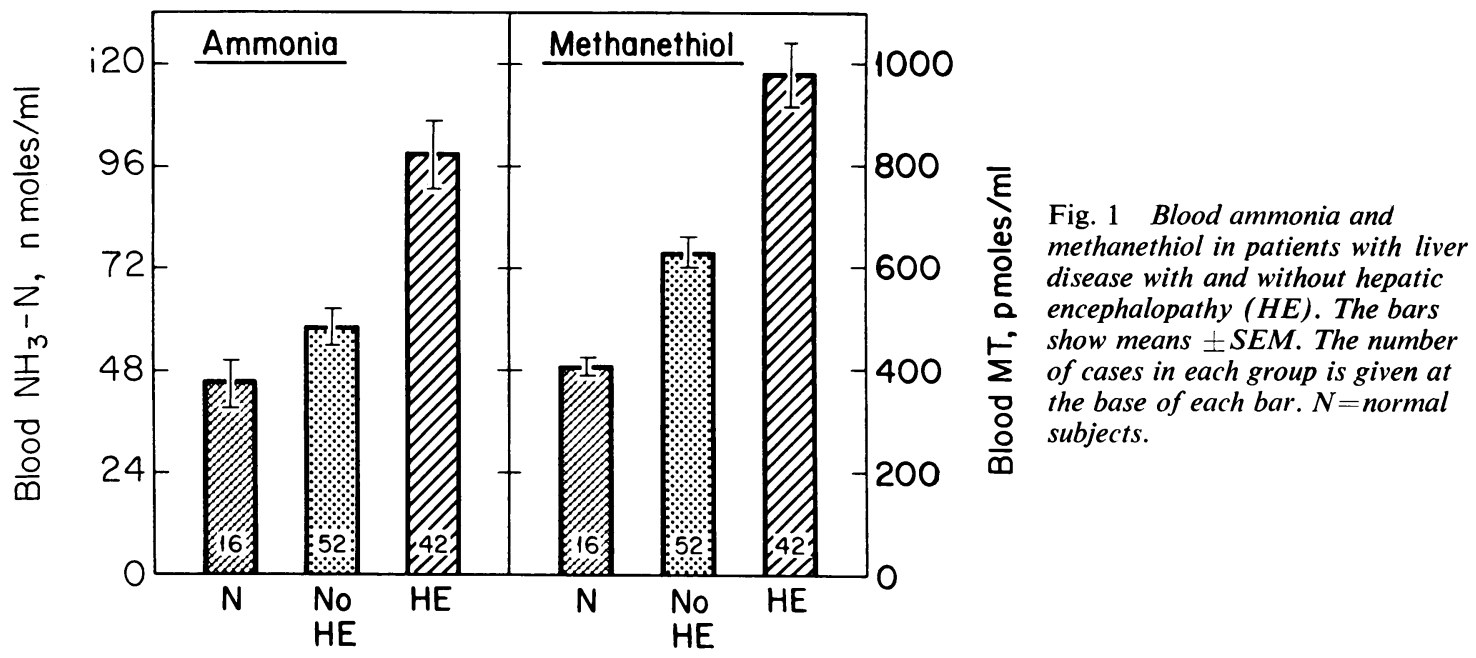

$\mathrm{pmol} / \mathrm{ml}$, and the highest blood ammonia 235 $\mathrm{nmol} / \mathrm{ml}$. In the absence of overt HE, blood ammonia was abnormal in $13 \%$ of patients, methanethiol in $64 \%$, and one or the other in $67 \%$. In the presence of overt HE blood ammonia was abnormal in $48 \%$ of patients, methanethiol in $93 \%$, and one or the other in $98 \%$. Thus, with either type of patient, the incidence of abnormal values of methanethiol was significantly greater than with ammonia $(P<0.001)$. Among patients without overt HE only

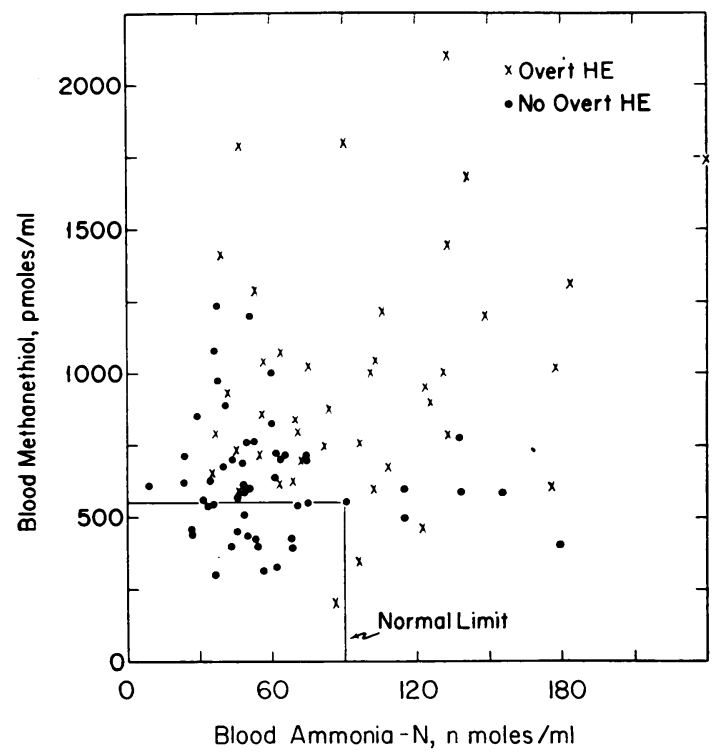

Fig. 2 Two-dimensional plot of individual blood methanethiol and ammonia values observed in patients with and without overt $H E$.
$8 \%$ had methanethiol values of $1000 \mathrm{pmol} / \mathrm{ml}$ or more, and $15 \%$ values of $800 \mathrm{pmol} / \mathrm{ml}$ or more. In contrast, in those patients with overt $\mathrm{HE}, 43 \%$ had blood methanethiol of $1000 \mathrm{pmol} / \mathrm{ml}$ or more and

\section{Encephalopathy improved. Survived.}

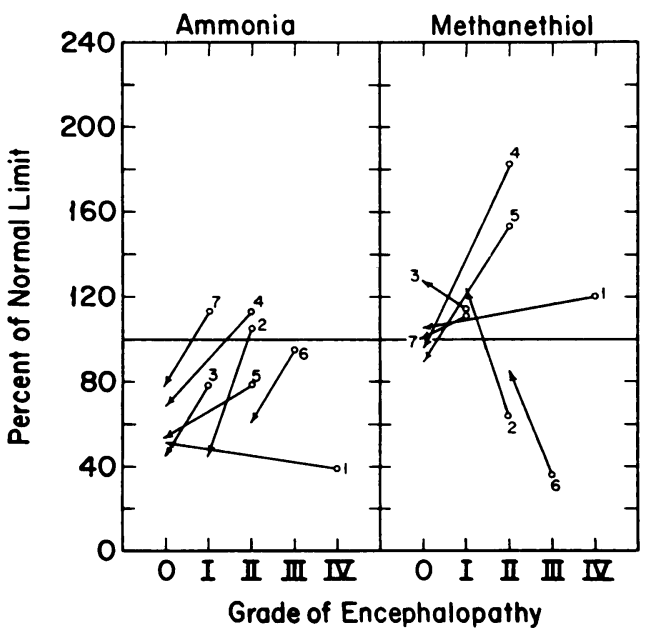

Fig. 3 Change in blood ammonia and methanethiol values in relation to change in clinical grade of $\mathrm{HE}$ in seven patients with improvement in encephalopathy. In these patients the arrow indicates the direction of change and the values when the encephalopathy was the least. The circles indicate values when the encephalopathy was at its worst. The numbers by the lines indicate the individual patients. The grade of encephalopathy is given on the abscissa. The values of ammonia and methaneihiol expressed as a percentage of their upper limits of normal $(90 \mathrm{nmol} / \mathrm{ml}$ and $550 \mathrm{pmol} / \mathrm{ml}$ respectively) are given on the ordinate. 
$60 \%$ values of $800 \mathrm{pmol} / \mathrm{ml}$ or more. Only $7 \%$ of these patients had a blood methanethiol value of less than $600 \mathrm{pmol} / \mathrm{ml}$, while $48 \%$ of the patients without $\mathrm{HE}$ had values below $600 \mathrm{pmol} / \mathrm{ml}$. These differences between the patients with and without $\mathrm{HE}$ were highly significant $(\mathbf{P}<0.001)$.

Of the 20 patients with $\mathrm{HE}$ who had serial measurements, seven showed improvement in their encephalopathy and survived. Fig. 3 shows blood ammonia and methanethiol values of these patients expressed as a percentage of their upper normal limits $(90 \mathrm{nmol} / \mathrm{ml}$ and $550 \mathrm{pmol} / \mathrm{ml}$ respectively). The values at each patient's worst and best mental state are connected by a line indicating the direction of change in encephalopathy. In these patients all but one ammonia value decreased, consistent with the change in mental state. However, based upon the $95 \%$ confidence limits derived from the test-retest determinations in the 10 clinically stable cirrhotics, none of the individual changes was significant. Three of the methanethiol changes (patients 1, 3, and 7) were also insignificant. The methanethiol values in patients 2 and 6 increased as encephalo-

Encephalopathy worsened. Died.

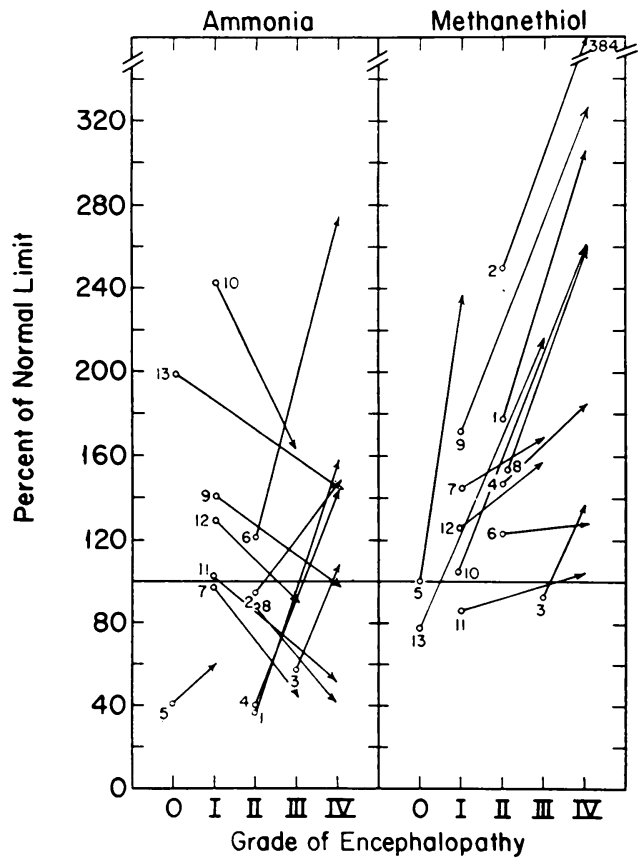

Fig. 4 Change in blood ammonia and methanethiol values in relation to change in grade of $H E$ in 13 patients with worsened encephalopathy. In these patients who died the arrow indicates the direction of change and the values when the encephalopathy was at its worst. The circles indicate values when the encephalopathy was the least. Remainder of legend as in Fig. 3. pathy improved. Protein starvation before admission to hospital may have depressed their initial methanethiol values.

The remaining 13 patients who were followed serially died of their disease. Figure 4 shows the vectors in these patients. In six of the 13, changes in both blood ammonia and methanethiol were consistent with the clinical changes in mental state. However, inconsistencies between ammonia and methanethiol in individual patients occurred. Thus patients 1,2 , and 5 had comparatively much higher methanethiol than ammonia values, and patient 6 had a preterminal ammonia value that was much higher, relatively, than his methanethiol value, which was practically unchanged. In seven of the patients, changes in blood ammonia, unlike methanethiol, were not consistent with the clinical changes in mental state. All seven patients had preterminal ammonia values less than the initial value when the clinical estimate of encephalopathy was at least two grades lower, though most of the individual changes were not significant. None of the methanethiol values decreased in these patients, though the change in patient 11 was probably insignificant and certainly not commensurate with the change in clinical severity. Considering the entire group of 13 patients who died, the average ammonia value when the encephalopathy was the least was $95 \pm 15 \mathrm{nmol} / \mathrm{ml}$ (mean $\pm \mathrm{SEM}$ ), and when the encephalopathy was the worst it was $104 \pm 16 \mathrm{nmol} / \mathrm{ml}$. The average difference of $10 \pm 19 \mathrm{nmol} / \mathrm{ml}$ was insignificant $(t=0.53, \mathrm{P}>0.6)$. The corresponding values for methanethiol were $746 \pm 72 \mathrm{pmol} / \mathrm{ml}$ and $1211 \pm 128$ $\mathrm{pmol} / \mathrm{ml}$. The average difference of $465 \pm 92$ was significant $(t=5 \cdot 1, \mathrm{P}<0.001)$.

Of the 20 patients with serial measurements, 17 $(85 \%)$ had directional changes in methanethiol and $12(60 \%)$ directional changes in ammonia that were consistent with the direction of clinical change. Among the 13 patients who died in hepatic coma, all had directional changes in methanethiol that were similar to the direction of clinical change. If changes among the entire group of 20 patients were only counted when they exceeded the $95 \%$ confidence limits derived from the test-retest determinations in the 10 clinically stable cirrhotics, only $13(65 \%)$ had methanethiol and three $(15 \%)$ ammonia changes that were consistent with the clinical change. The difference between $65 \%$ and $15 \%$ was significant $(\mathbf{P}<\mathbf{0 . 0 1 )}$ by the Chi-squared test corrected for small numbers.

\section{Discussion}

In any relatively unselected sample of patients with liver disease such as ours, the more severe the hepatic 
failure the more likely that encephalopathy will occur. Thus, the presence of hepatic encephalopathy is usually an indication in itself of severe liver disease. The ordinary tests of liver function do not differentiate the patients with encephalopathy from those without encephalopathy. Some measurements such as the blood ammonia and certain plasma amino acids will do so inefficiently, there being great overlap among groups. No measurement has yet been found that will completely separate patients with encephalopathy from those without encephalopathy, and it is not likely that such complete separation will ever be achieved. The blood methanethiol is simply an additional measurement like ammonia that reflects both hepatic dysfunction and the extent to which blood from the intestine bypasses the liver. As a liver function test it differentiates patients with liver disease from those without liver disease. The magnitude of its abnormality is what differentiates those with from those without encephalopathy. The blood methanethiol concentration appears to correlate at least as well as the blood ammonia with the development of HE. Having both measurements is more useful then either one alone. We look upon the blood methanethiol measurement as an adjunct to the blood ammonia in the quantitative evaluation of a patient with possible HE. An isolated determination of either of these measurements at one point in the patient's course may not be clinically useful. However, serial measurements are helpful in following the patient with HE, particularly as an indicator of response to therapy. Like ammonia, methanethiol may also play a pathogenetic role in HE. Evidence for this comes from both animal experiments and human studies.

Methanethiol administered by injection or inhalation produces reversible coma in rats. ${ }^{1}$ Similarly, feeding of methionine to shunted dogs produces reversible coma as does intravenous administration of methanethiol.? Methanethiol acts synergistically with both ammonia and fatty acids, enhancing the toxicity of each. ${ }^{1}$ Thus, subcoma doses of methanethiol administered with subcoma amounts of either fatty acids or ammonia produced coma in experimental animals. Blood levels of methanethiol in rats with experimentally produced fulminant hepatic failure and coma were similar in magnitude to those observed in patients with hepatic coma. ${ }^{4}$ The concentration of methanethiol in the brain of such rats in hepatic coma was increased five-fold. The mechanism of methanethiol-induced coma is unclear. Waller ${ }^{8}$ demonstrated methanethiol inhibition of mitochondrial respiration in rat livers. Methanethiol has also been shown to reversibly inhibit brain microsomal $(\mathrm{Na}+, \mathrm{K}+)$-ATPase. ${ }^{9}$ Both these actions may be involved in the pathogenesis of HE, but ad- ditional work in this area is required.

In man, methanethiol has been. indirectly implicated as a cause of hepatic encephalopathy. Because methionine deficiency caused hepatic injury in rats, methionine supplementation was once considered to be therapeutic for patients with hepatic decompensation. Then Watson ${ }^{10}$ and Kinsell et al. ${ }^{11}$ reported patients with cirrhosis who developed confusion and disorientation after methionine administration. Subsequent studies by Phear and coworkers ${ }^{12}$ showed that oral methionine ingestion caused HE in many chronic cirrhotics. Neuropsychiatric deterioration occurred without significant increase in blood ammonia levels and the toxic effects were blocked by a broad spectrum antibiotic. It was concluded that the deleterious effect of methionine was due to some toxic breakdown product of methionine other than ammonia.

These observations were clarified by Chen and coworkers $^{3}$ who found that the concentration of dimethyl sulphide in the breath of cirrhotics who were treated with methionine was related to both the intensity of breath odour and the encephalopathy that resulted. Dimethyl sulphide is rapidly formed from methanethiol, being its primary metabolic derivative. Like methanethiol, dimethyl sulphide has been shown to produce reversible coma in rats. ${ }^{1}$ Thus, natural products of methionine breakdown in the gut, methanethiol and dimethyl sulphide, could be related to the encephalopathic effects observed in cirrhotics ingesting an excess of methionine. It is also possible that reducing methionine in the diet may be beneficial to such patients. Greenberger and associates ${ }^{13}$ successfully used a vegetable protein diet low in methionine to treat patients with particularly severe chronic portal systemic encephalopathy, though they did not establish that the beneficial effect was due to the reduction in methionine. Finally, we now report blood levels of methanethiol that are significantly higher in cirrhotics with overt encephalopathy than in those without overt encephalopathy.

It is thus reasonable to postulate a pathogenetic role for methanethiol in hepatic encephalopathy, and we think that measurements of blood mercaptans will have significance as indicators of both the presence of $\mathrm{HE}$ and of one of the pathogenic factors.

We are indebted to Nadine Steel for excellent technical assistance.

\section{References}

'Zieve L, Doizaki WM, Zieve FJ. Synergism between mercaptans and ammonia or fatty acids in the production of coma: a possible role for mercaptans in the 
pathogenesis of hepatic coma. J Lab Clin Med 1974; 83: 16-28.

${ }^{2}$ Challenger F, Walshe JM. Methyl mercaptan in relation to foetor hepaticus. Biochem $J$ 1955; 59: 372-5.

${ }^{3}$ Chen S, Zieve L, Mahadevan V. Mercaptans and dimethylsulfide in the breath of patients with cirrhosis of the liver. J Lab Clin Med 1970; 75: 628-35.

${ }^{4}$ Doizaki WM, Zieve L. An improved method for measuring blood mercaptans. J Lab Clin Med 1977; 90: 849-55.

${ }^{5}$ Parsons-Smith BG, Summerskill WHJ, Dawson AM, Sherlock S. The electroencephalograph in liver disease. Lancet 1957; ii: 867-71.

${ }^{6}$ Reinhold JG, Chung CC. Formation of artifactual ammonia in blood by action of alkali. Its significance for the measurement of blood ammonia. Clin Chem 1961; 7: 54-69.

'Merino GE, Jetzer T, Doizaki WM, Najarian JS.
Methionine-induced hepatic coma in dogs. Am J Surg 1975; 130: 41-46.

${ }^{8}$ Waller RL. Methanethiol inhibition of mitochondrial respiration. Toxicol Appl Pharmacol 1977; 42: 111-7. ${ }^{9}$ Quarfoth G, Ahmed K, Foster D, Zieve L. Action of methanethiol on membrane $(\mathrm{Na}+, \mathrm{K}+)$-ATPase of rat brain. Biochem Pharmacol 1976; 25: 1039-44.

${ }^{10}$ Watson CJ. The prognosis and treatment of hepatic insufficiency. Ann Intern Med 1949; 31 : 405-23.

${ }^{11}$ Kinsell LW, Harper HA, Giese GK, Margen S, McCallie DP, Hess JR. Studies of methionine metabolism. II. Fasting plasma methionine levels in normal and hepatopathic individuals in response to daily methionine ingestion. J Clin Invest 1949; 28: 1439-50.

${ }^{12}$ Phear EA, Ruebner B, Sherlock S, Summerskill WHJ. Methionine toxicity in liver disease and its prevention by chlortetracycline. Clin Sci 1956; 15: 93-117. 